\title{
Analisis Profil Pemahaman dan Ketertarikan Mahasiswa Biologi pada STEM Education
}

\author{
Eka Kurniati $^{1}$, Hadi Suwono ${ }^{1}$, Ibrohim ${ }^{1}$ \\ ${ }^{1}$ Pendidikan Biologi-Universitas Negeri Malang
}

\section{INFO ARTIKEL}

\section{Riwayat Artikel:}

Diterima: 07-08-2020

Disetujui: 15-12-2020

Kata kunci:
interest and understanding of
STEM;
biology student;
ketertarikan dan pemahaman
STEM;
mahasiswa biologi

\author{
Alamat Korespondensi: \\ Eka Kurniati \\ Pendidikan Biologi \\ Universitas Negeri Malang \\ Jalan Semarang 5 Malang \\ E-mail: eka.kurniati.1803418@students.um.ac.id
}

\begin{abstract}
STEM Education is currently attracting the attention of many parties including biology students to apply in the classroom. Students' understanding and interest in STEM Education are two basic things to support the successful implementation of STEM Education. Nevertheless, studies on student profiles related to the understanding and interest of STEM Education especially in biology students are still difficult to find. The objectives of this article was to investigate the profile of understanding and interest in STEM, which was analyzed in a descriptive quantitative manner by conducting a survey of 42 masters in biology education. The findings indicate that biology students have basic knowledge of STEM education and a relatively high interest in STEM education. As $79 \%$ of prospective educators claim they are interested in studying STEM, and 62\% say that it is necessary for teachers to consider STEM. Institution support is deemed necessary to be increased and optimized in order to enhance students' knowledge and readiness in implementing STEM.
\end{abstract}

ABSTRAK

\begin{abstract}
Abstrak: STEM Education saat ini sedang menarik perhatian banyak pihak termasuk mahasiswa biologi untuk diterapkan di dalam kelas. Pemahaman dan ketertarikan mahasiswa pada STEM Education merupakan dua hal yang mendasar untuk menunjang keberhasilan implementasi STEM Education. Meskipun demikian, studi mengenai profil mahasiswa terkait pemahaman dan ketertarikan STEM Education khususnya pada mahasiswa biologi masih sulit ditemukan. Tujuan dari penelitian ini untuk mengeksplor profil pemahaman dan ketertarikan pada STEM yang dikaji secara deskriptif kuntitatif dengan melakukan survei pada 42 mahasiswa magister Pendidikan Biologi. Hasil menunjukkan bahwa mahsiswa Biologi telah memiliki pengetahuan dasar terkait STEM Education dan memiliki ketertarikan yang relatif tinggi terhadap STEM Education. Sebanyak 79\% mahasiswa calon pendidik mengklaim tertarik mendalami STEM dan $62 \%$ menyatakan bahwa penting bagi guru untuk memahami STEM. Dukungan instansi dianggap perlu ditingkatkan dan dioptimalkan untuk dapat menambah pengetahuan dan kesiapan mahasiswa dalam mengimplementasikan STEM.
\end{abstract}

Sejumlah negara baik negara maju ataupun negara berkembang melakukan berbagai inovasi dan reformasi untuk menyiapkan warga negaranya memiliki keterampilan abad-21. Keterampilan abad-21 merupakan keterampilan yang dibutuhkan untuk bersaing secara global. Salah satu cara efektif untuk membekali masyarakat menguasi keterampilan abad-21 yaitu melalui jalur pendidikan (Redhana, 2019). Saat ini, salah satu isu penting dalam tren dunia pendidikan yaitu tentang STEM Education (Gonzalez \& Kuenzi, 2012). STEM Education merupakan integrasi dari science, technology, engineering dan mathematics yang bertujuan untuk menciptakan lingkungan belajar yang berpusat pada siswa dimana siswa mampu menyelidiki dan merekayasa solusi sebuah masalah serta dapat menjelaskannya dengan fokus sosial, emosional, fisik, dan akademik (Corlu \& Capraro, 2014). STEM Education mengintegrasikan beragam cabang ilmu yang digunakan untuk menyelesaikan permasalahan di dunia nyata (Labov, Singer, George, Schweingruber, \& Hilton, 2009; Sanders, 2009). Lebih lanjut, kecakapan pada bidang STEM dinilai sangat penting untuk dapat bersaing dalam dunia kerja pada abad-21 (Beatty, 2011; Mizell \& Brown, 2016).

STEM Education penting sebagai dasar untuk meningkatkan daya saing global dan memastikan masa depan ekonomi suatu negara melalui sumberdaya manusia yang berkualitas (Breiner, Harkness, Johnson, \& Koehler, 2012). Indonesia merupakan negara yang mendapatkan bonus demografi dimana sumber daya manusia usia produktif akan melimpah sampai tahun 2035. Hal ini akan menjadi tantangan tersendiri apabila tidak dimanfaatkan dan dipersiapkan dengan baik. Seperti yang dikemukakan oleh Bybee, (2010) dan Kelley \& Knowles (2016) jika hal tersebut tidak diantisipasi sejak dini, maka akan membahayakan keamanan global dan stabilitas ekonomi. Tonggak penting dalam keberhasilan implementasi STEM Education 
yaitu peranan guru sebagai pendidik. Guru harus memiliki kemampuan untuk mengintegrasikan STEM dalam proses belajar mengajar agar tujuan mengembangkan keterampilan abad-21 dapat dicapai dengan optimal (Stohlmann, Moore, \& Roehrig, 2012). Banyak guru yang tertarik dengan STEM, tetapi mereka tidak percaya diri untuk mengimplementasikannya (Shernoff, Sinha, Bressler, \& Ginsburg, 2017).

Beberapa studi telah dilakukan untuk mengetahui profil siswa maupun guru terhadap STEM. Penelitian yang dilakukan oleh Nisraeni, Rustam, \& Iriyadi (2020) menunjukkan hasil bahwa mahasiswa matematika sangat antusias dan tertarik pada STEM, tetapi pengembangan profesional untuk menunjang hal tersebut dirasa masih kurang. Minat dan ketertarikan pada STEM memang baru-baru ini juga mendapat perhatian karena adanya kesenjangan antara siswa yang memilih STEM dan kebutuhan tenaga kerja STEM (Vulperhorst, Wessels, Bakker, \& Akkerman, 2018). Penelitian Struyf, De Loof, Pauw, \& Petegem, (2019) menyatakan bahwa lingkungan belajar yang mengintegrasikan STEM akan menarik dan mendukung keterlibatan siswa. Penerapan STEM Education dipengaruhi oleh pengetahuan dan sikap guru pada STEM (Sujarwanto, Madlazim, \& Ibrahim, 2019). Hasil survei pada guru sains di Indonesia menyatakan bahwa tingkat penerapan STEM masih sedang dan pengetahuan tentang STEM terkategori rendah (Parmin, Saregar, Deta, \& El Islami, 2020). Artikel ini bertujuan untuk mengetahui profil pemahaman dan ketertarikan mahasiswa Biologi pada STEM Education.

\section{METODE}

Penelitian ini merupakan penelitian survei. Survei dilakukan dengan memberikan satu set kuesioner yang terdiri atas 12 pertanyaan untuk mengeksplor profil pemahaman dan ketertarikan mahasiswa magister pendidikan biologi terhadap STEM Education. Partisipan survei terdiri atas 42 mahasiswa magister pendidikan biologi dengan rincian 10 laki-laki, dan 32 perempuan. Jumlah partisipan merupakan $66 \%$ dari total keseluruhan mahasiswa magister Pendidikan Biologi angkatan 2018 di Universitas Negeri Malang. Semua partisipan secara sukarela mengisi kuesioner yang dibagikan melalui google form. Berdasarkan profil data diri mahasiswa, diketahui 54.5\% mahasiswa pernah mengajar selain program Kuliah Praktik Lapangan (KPL) dari kampus dan $45.5 \%$ belum memiliki pengalaman mengajar. Pengalaman mengajar minimal tiga minggu hingga paling lama tiga tahun. Sebanyak $45.5 \%$ mengajar di SMA/MA, 33.3\% di SMP/MTs, dan 6.1\% SD/MI. Data dianalisis secara statistik persentase dan konten analisis dengan bantuan software Nvivo. Hasil disajikan dalam bentuk tabel, diagram, dan narasi.

\section{HASIL}

Hasil analisis terkait profil pengetahuan dan ketertarikan mahasiswa pada STEM Education diawali dengan menganalisis hasil survei pengetahuan mahasiswa tentang STEM Education. Mahasiswa memberikan respon apakah mereka benar-benar mengetahui, hanya sedikit mengetahui atau bahkan tidak mengetahui sama sekali tentang STEM Education. Data disajikan pada gambar 1 .

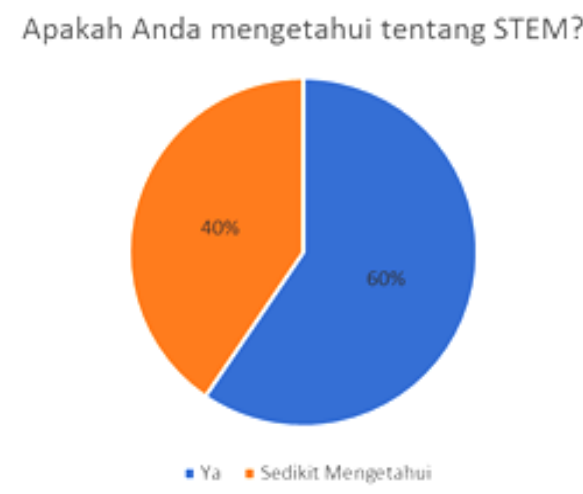

\section{Gambar 1. Hasil Persentase Pengetahuan STEM Mahasiswa}

Berdasarkan gambar 1, mahasiswa yang mengetahui STEM Education lebih banyak dibandingkan yang sedikit mengetahui atau tidak mengetahui sama sekali. Sebanyak $60 \%$ mengklaim dirinya mengetahui tentang STEM dan $40 \%$ lainnya mengklaim sedikit mengetahui tentang STEM. Tidak ada mahasiswa yang mengklaim bahwa mereka tidak tahu sama sama sekali tentang STEM.

Selain itu, sejauh mana pengetahuan mahasiswa pada STEM Education juga dieksplorasi. Untuk melihat pengetahuan atau persepsi mahasiswa tentang STEM dilakukan analisis jawaban menggunakan software Nvivo. Hasil analisis jawaban mahasiswa disajikan dalam gambar 2 . 


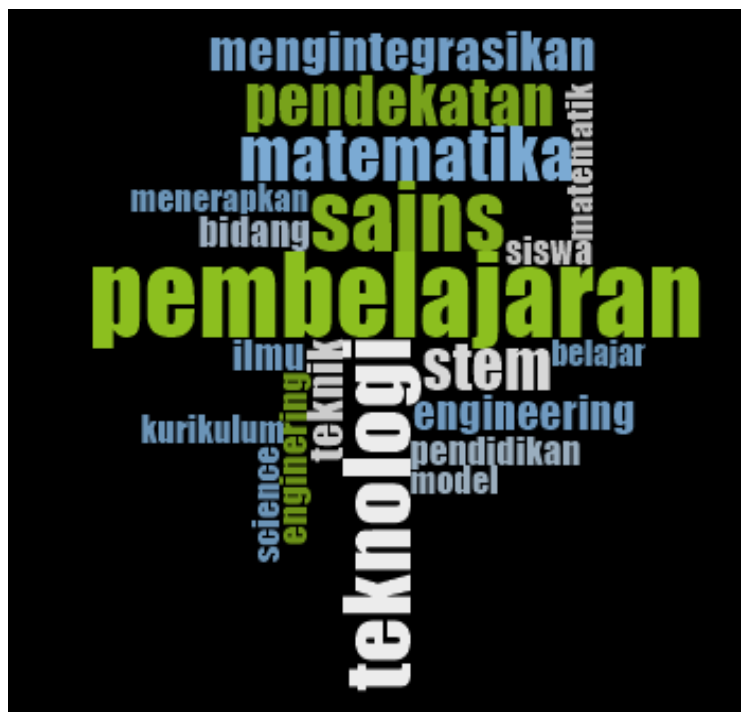

\section{Gambar 2. Hasil Analisis Pengetahuan STEM menggunakan Word Frekuensi Software NVivo}

Gambar 2 menunjukkan 20 frekuensi kata yang paling sering muncul pada jawaban kuesioner mahasiswa mengenai apa yang mereka ketahui tentang STEM Education. Beberapa kata tersebut diantaranya "pembelajaran, sains, teknologi, matematika, pendekatan, stem, mengintegrasikan, teknik, engineering, kurikulum, model, pendidikan." Berdasarkan hasil analisis dapat diketahui bahwa secara dominan mahasiswa memahami bahawa STEM Education merupakan integrasi bidang sains, teknologi, teknik dan matematika di dalam suatu pembelajaran. Meskipun beberapa diantaranya masih menyebutkan hal yang berbeda-beda dengan istilah kurikulum, pendekatan bahkan model pembelajaran.

Mahasiswa juga memberikan respons terkait beberapa hal yang perlu disiapkan dalam pengimplementasian STEM di Indonesia. Bagian ini memberikan jawaban terbuka sehingga memungkinkan jawaban siswa dikodekan dalam beberapa tema. Jawaban mahasiswa dikodekan dalam empat tema seperti terlihat pada tabel 1.

Tabel 1. Frekuensi pengodean terkait persiapan dalam implementasi STEM

\begin{tabular}{lc}
\hline Tema & Frekuensi \\
\hline Kesiapan guru & 37 \\
Fasilitas pendukung & 27 \\
Kurikulum & 11 \\
Kesiapan siswa & 8 \\
\hline
\end{tabular}

Tabel 1 menunjukkan bahwa mahasiswa menganggap kesiapan guru merupakan hal yang utama dalam implementasi STEM. Selain itu, fasilitas berupa sarana dan prasarana pendukung juga dianggap sebagai komponen yang harus dipersiapkan dengan matang. Hal ini dikonfirmasi dari jawaban mahasiswa terhadap pertanyaan "hal apa yang akan Anda lakukan jika Anda diminta menerapkan STEM di kelas?" Respons yang diberikan seperti: "menelaah materi dengan mengaitkan materi pada empat disiplin ilmu"; "mencari permasalahan yang berhubungan dengan empat bidang yang dikaji"; "saya perlu menyiapkan media dan sarana pendukung pembelajaran STEM"; dan "saya perlu mempelajari STEM terlebih dahulu." Sebagai tambahan, beberapa mahasiswa menganggap penting untuk melakukan kolabirasi antar guru mata pelajaran. Mahasiswa menyampaikan bahwa "melakukan kolaborasi antar guru STEM dan lintas disiplin ilmu di sekolah merupakan hal yang penting."

Selain survei pengetahuan mahasiswa terkait STEM, kuesioner juga mengukur tanggapan mengenai perlunya menerapkan STEM dalam kurikulum, pentingnya memahami STEM untuk calon pendidik dan ketertarikan individu untuk mendalami STEM. Tabulasi data secara rinci disajikan pada gambar 3. 


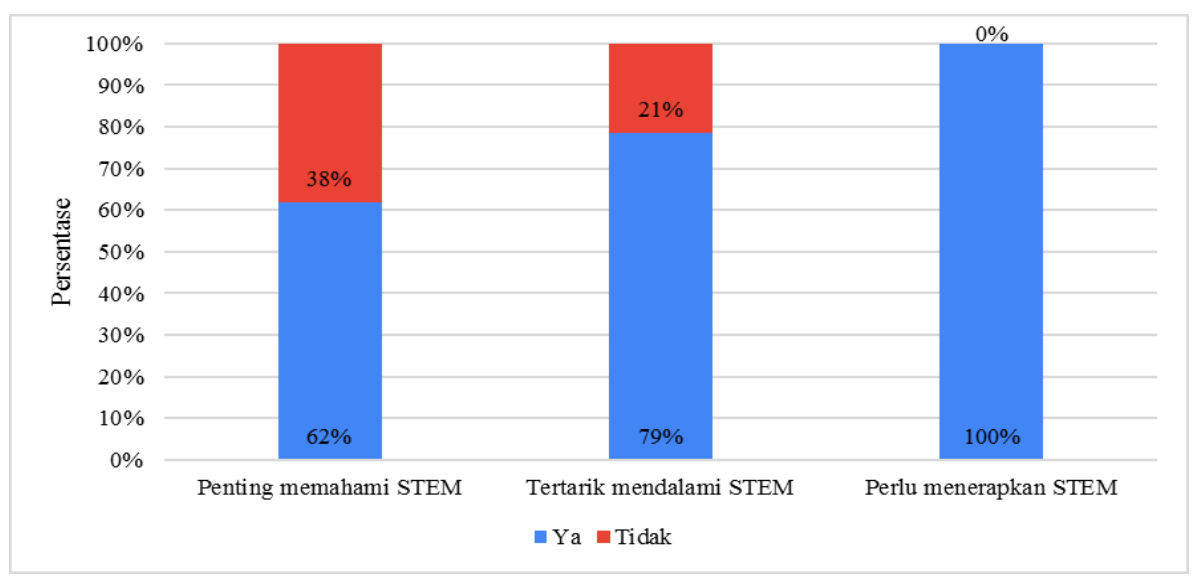

\section{Gambar 3. Hasil Tanggapan Mahasiswa Mengenai Keperluan, Kepentingan dan Ketertarikan pada STEM}

Berdasarkan hasil analisis gambar 3 diketahui seluruh partisipan (100\%) mengklaim perlunya menerapakan STEM Education dalam kurikulum dengan berbagai macam alasan yang mendukungnya. Beberapa alasan tersebut diantaranya "perlu mengikuti perkembangan zaman dan sebagai suatu upaya untuk menghadapi permasalahan global, guru perlu membekali siswa menjadi pribadi yang memiliki keterampilan abad-21 yaitu kritis, kreatif dan dapat memecahkan permasalahan sehari-hari, menyiapkan siswa yang kompetitif dan memiliki pola pikir untuk terus berkembang, dan STEM dapat meningkatkan mutu pendidikan di Indonesia". Sementara itu, sebanyak 62\% menyatakan bahwa pentingnya guru untuk memahami STEM dan 38\% menyatakan cukup penting untuk guru memahami STEM. Hal ini juga didukung dengan data bahwa sebanyak $79 \%$ guru tertarik mendalami STEM dan hanya $21 \%$ dari total partisipan merasa kurang tertarik mendalami STEM.

\section{PEMBAHASAN}

Semakin berkembangnya STEM Education, implementasi STEM Education di kelas semakin masif. Meskipun demikian, informasi terkait pemahaman dan ketertarikan mahasiswa pada STEM masih sedikit khususnya pada subjek mahasiswa biologi. Penelitian ini menunjukkan bahwa mahasiswa Biologi telah memiliki pengetahuan dasar terkat STEM. Selain itu, mahasiswa biologi juga memiliki ketertarikan yang cukup tinggi terhadap implementasi STEM. Berdasarkan survei diketahui sebanyak 79\% mahasiswa calon pendidik tertarik mendalami STEM dan $62 \%$ menyatakan pentingnya seorang guru untuk memahami STEM. Menurut Ramli et al. (2017), kesiapan guru dalam mengimplementasikan STEM masih rendah. Banyak guru tidak memiliki kepercayaan diri membelajarkan STEM dan tidak familiar dengan STEM (Shernoff et al., 2017). Faktor yang menyebabkan hal tersebut yaitu keterbatasan pengetahuan guru diluar bidang keahlian yang diambil pada jenjang perguruan tinggi (Avery \& Reeve, 2013; Wilson, 2011). Sebagai calon pendidik penting untuk memiliki pengetahuan pedagogis dan pengetahuan konten. Pengetahuan konten dan pedagogis adalah dasar untuk menerapkan STEM di kelas (Putra \& Kumano, 2018). Selain itu, kepedulian guru terhadap STEM dan pengaruh pengembangan profesional menjadi faktor kesuksesan dalam implementasi STEM (Dare, Ellis, \& Roehrig, 2018). Pengembangan profesional dapat memfasilitasi guru untuk mendapatkan pengetahuan pedagogis dan konten jika program yang dilakukan berkelanjutan,kolaboratif, koheren dan reflektif (Estapa \& Tank, 2017). Hal ini tentu tidak jauh dari peran suatu lembaga yang menaugi lulusan-lulusan calon pendidik agar tetap konsisten untuk mendukung implementasi STEM di sekolah-sekolah atau instansi-instansi mereka bekerja atau mengabdi nanti. Menurut Keiler (2018), lingkungan belajar yang tidak lain adalah pendidikan tinggi menjadi sarana bagi calon pendidik untuk mengubah identitas dan meningkatkan pengembangan profesionalnya. Oleh sebab itu, implementasi STEM perlu juga mempertimbangkan kesiapan dukungan sistem pendidikan seperti kurikulum (Suwarma \& Kumano, 2014).

Pendidikan tinggi semakin dituntut untuk mencetak populasi sumberdaya manusia yang berkualitas dan didorong untuk terlibat dalam reformasi STEM Education (Carlisle \& Weaver, 2018). Universitas Negeri Malang adalah salah satu universitas di Indonesia yang mendeklarasikan sebagai kampus yang menerapkan kurikulum dilengkapi dengan pendekatan kapabilitas dan transdisipliner per tahun 2018 (Sulton et al., 2018). Pendekatan kapabilitas merupakan suatu saran untuk mengarahkan individu memiliki keahlian sesuai dengan profesi yang dipilih dan mengembangkan keahlian dalam berbagai bidang sesuai dengan tuntutan kehidupan baik selama perkuliahan ataupun pasca perkuliahan. Sementara itu, pendekatan transdisiplin memberikan kebebasan mahasiswa memprogram matakuliah sesuai dengan kapabilitas masing-masing. Mahasiswa dapat mengambil matakuliah lintas prodi dan fakultas, dalam rangka mengembangkan keutuhan kapabilitasnya sehingga proses belajar lintas disiplin bagi mahasiswa terwadahi dengan sistematis dan terintegrasi (Baskara \& Prahedhiono, 2018). 
Penelitian ini dapat memberikan gambar awal mengenai profil mahasiswa terkait STEM Education. Hasil penelitian ini dapat menjadi pertimbangan bagi dosen dan pembuat kebijakan tingkat universitas dalam mempersiapkan calon guru STEM di sekolah. Sebagai tambahan, mahasiswa hendaknya lebih memperkaya pengetahuan terkait STEM yang dapat didukung oleh peran instansi dalam menerapkan program-program terkait STEM Education yang sesuai dengan karaktersitik mahasiswa.

\section{SIMPULAN}

Berdasarkan hasil penelitian diketahui bahwa mahasiswa Biologi memiliki ketertarikan yang relatif tinggi terhadap STEM Education. Mahasiswa biologi juga menunjukkan bahwa mereka telah memiliki pengetahuan dasar terkait STEM Education. Meskipun demikian, dukungan univeristas tetap dianggap perlu ditingkatkan untuk dapat menambah pengetahuan dan kesiapan mahasiswa dalam mengimplementasikan STEM. Penerapan kebijakan atau pengoptimalan kurikulum dengan pendekatan kapabilitas dan transdisiplin yang sejalan dengan konsep STEM perlu dimaksimalkan lagi dengan mengenalkan kajian STEM di kelas secara eksplisit.

Penelitian ini terbatas pada jumlah sampel dimana hanya mahasiswa magister Pendidikan Biologi 2018 yang secara sukarela mengisi kuesioner. Penelitian selanjutnya dapat dilakukan dengan jumlah sampel yang lebih banyak dan lebih beragam agar representatif dan hasil dapat digeneralisasi lebih luas. Selain itu, data dapat diperkuat dengan melakukan metode pengumpulan data lain, seperti wawancara pada beberapa mahasiswa, dosen atau pengembang kurikulum agar hasil lebih valid dan kredibel.

\section{DAFTAR RUJUKAN}

Avery, Z. K., \& Reeve, E. M. (2013). Developing Effective STEM Professional Development Programs. Journal of Technology Education, 25(1), 55-69. https://doi.org/10.21061/jte.v25i1.a.4

Baskara, D. S., Sulthon., \& Prahedhiono, H. (2018). Model Layanan untuk Mendukung Pembelajaran Transdisipliner. Jurnal Pendidikan: Teori, Penelitian, dan Pengembangan, 3(9), 1147-1150.

Breiner, J. M., Harkness, S. S., Johnson, C. C., \& Koehler, C. M. (2012). What Is STEM? A Discussion about Conceptions of STEM in Education and Partnerships. School Science and Mathematics, 112(1), 3-11. https://doi.org/10.1111/j.19498594.2011.00109.x

Bybee, R. W. (2010). What is STEM Education? Science. https://doi.org/10.1126/science.1194998

Carlisle, D. L., \& Weaver, G. C. (2018). STEM Education Centers: Catalyzing the Improvement of Undergraduate STEM Education. International Journal of STEM Education, 5(1). https://doi.org/10.1186/s40594-018-0143-2

Corlu, M. S., M., R., \& Capraro, M. M. (2014). Introducing STEM Education: Implications for Educating Our Teachers for the Age of Innovation. Egitim ve Bilim, 39(171), 74-85.

Dare, E. A., Ellis, J. A., \& Roehrig, G. H. (2018). Understanding Science Teachers' Implementations of Integrated STEM Curricular Units Through a Phenomenological Multiple Case Study. International Journal of STEM Education, 5(1). https://doi.org/10.1186/s40594-018-0101-z

Estapa, A. T., \& Tank, K. M. (2017). Supporting Integrated STEM in the Elementary Classroom: A Professional Development Approach Centered on an Engineering Design Challenge. International Journal of STEM Education, 4(1). https://doi.org/10.1186/s40594-017-0058-3

Gonzalez, H. B., \& Kuenzi, J. (2012). What Is STEM Education and Why Is It Important? Congressional Research Service, (August), 1-15. Retrieved from https://www.ccc.edu/departments/Documents/STEM_labor.pdf

Keiler, L. S. (2018). Teachers' Roles and Identities in Student-Centered Classrooms. International Journal of STEM Education, 5(1). https://doi.org/10.1186/s40594-018-0131-6

Kelley, T. R., \& Knowles, J. G. (2016). A Conceptual Framework for Integrated STEM Education. International Journal of STEM Education, 3(11). https://doi.org/10.1186/s40594-016-0046-z

Labov, J. B., Singer, S. R., George, M. D., Schweingruber, H. A., \& Hilton, M. L. (2009). Effective Practices in Undergraduate STEM Education Part 1: Examining the Evidence. CBE Life Sciences Education. https://doi.org/10.1187/cbe.09-06-0038

Mizell, S., \& Brown, S. (2016). The Current Status of STEM Education Research 2013-2015. Journal of STEM Education, $17(4), 52-56$.

Nisraeni, Rustam, A., \& Iriyadi, D. (2020). STEM Education for Prospective Teachers. Companion Proceedings of the SEADRIC 2019 (2020), 2019(July 2019), 68-72. https://doi.org/10.24071/seadr.2019.10

Parmin, P., Saregar, A., Deta, U. A., \& El Islami, R. A. Z. (2020). Indonesian Science Teachers' Views on Attitude, Knowledge, and Application of STEM. Journal for the Education of Gifted Young Scientists. https://doi.org/10.17478/jegys.647070

Putra, P. D. A., \& Kumano, Y. (2018). Energy Learning Progression and STEM Conceptualization among Pre-Service Science Teachers in Japan and Indonesia. New Educational Review. https://doi.org/10.15804/tner.2018.53.3.13

Ramli, A. A., Ibrahim, N. H., Surif, J., Bunyamin, M. A. H., Jamaluddin, R., \& Abdullah, N. (2017). Teachers' Readiness in Teaching STEM Education. Man in India, 97(13), 343-350. 
Redhana, I. W. (2019). Mengembangkan Keterampilan Abad ke-21 Dalam Pembelajaran Kimia. Jurnal Inovasi Pendidikan Kimia, 13(1), 2239-2253.

Shernoff, D. J., Sinha, S., Bressler, D. M., \& Ginsburg, L. (2017). Assessing Teacher Education and Professional Development Needs for the Implementation of Integrated Approaches to STEM Education. International Journal of STEM Education, 4(1), 1-16. https://doi.org/10.1186/s40594-017-0068-1

Stohlmann, M., Moore, T., \& Roehrig, G. (2012). Considerations for Teaching Integrated STEM Education. Journal of PreCollege Engineering Education Research, 2(1), 28-34. https://doi.org/10.5703/1288284314653

Struyf, A., De Loof, H., Boeve-de Pauw, J., \& Van Petegem, P. (2019). Students' Engagement in Different STEM Learning Environments: Integrated STEM Education as Promising Practice? International Journal of Science Education, 41(10), 1387-1407. https://doi.org/10.1080/09500693.2019.1607983

Sujarwanto, E., Madlazim, \& Ibrahim, M. (2019). Attitude, Knowledge, and Application of STEM Owned by Science Teachers. Journal of Physics: Conference Series. https://doi.org/10.1088/1742-6596/1417/1/012096

Sulton, Kamadi, W., Saryono, D., Sugeng, B., Hidayat, A., Ibrohim, ... Praherdhiono, H. (2018). Panduan Pengembangan Kurikulum Universitas Negeri Malang Tahun 2018. https://doi.org/10.1017/CBO9781107415324.004

Vulperhorst, J. P., Wessels, K. R., Bakker, A., \& Akkerman, S. F. (2018). How do STEM-Interested Students Pursue Multiple Interests in Their Higher Educational Choice? International Journal of Science Education, 40(8), 828-846. https://doi.org/10.1080/09500693.2018.1452306

Wilson, S. M. (2011). Effective STEM Teacher Preparation, Induction, and Professional Development. Paper Prepared for the Workshop of the Committee on Highly Successful Schools or Programs for K-12 STEM Education. 